\title{
BMJ Open Nutrition Questionnaires plus (NQplus) study, a prospective study on dietary determinants and cardiometabolic health in Dutch adults
}

\author{
Elske Maria Brouwer-Brolsma, Linde van Lee, Martinette T Streppel, \\ Diewertje Sluik, Anne M van de Wiel, Jeanne H M de Vries, Anouk Geelen, \\ Edith J M Feskens
}

To cite: Brouwer-Brolsma EM, van Lee L, Streppel MT, et al. Nutrition Questionnaires plus (NQplus) study, a prospective study on dietary determinants and cardiometabolic health in Dutch adults. BMJ Open 2018;8:e020228. doi:10.1136/ bmjopen-2017-020228

- Prepublication history for this paper is available online. To view these files, please visit the journal online (http://dx.doi org/10.1136/bmjopen-2017020228).

Received 24 October 2017 Revised 11 June 2018 Accepted 12 June 2018
D) Check for updates

(C) Author(s) (or their employer(s)) 2018. Re-use permitted under CC BY-NC. No commercial re-use. See rights and permissions. Published by BMJ.

Division of Human Nutrition, Wageningen University, Wageningen, The Netherlands

Correspondence to Dr Edith J M Feskens; Edith.Feskens@wur.nl

\section{ABSTRACT}

Purpose During the past decades, the number of people with cardiometabolic conditions substantially increased. To identify dietary factors that may be responsible for this increase in cardiometabolic conditions, the Nutrition Questionnaires plus (NQplus) study was initiated. The aim of this article is to provide an overview of the study design and baseline characteristics of the NQplus population.

Participants The NQplus study is a prospective cohort study among 2048 Dutch men (52\%) and women (48\%) aged $20-70$ years.

Findings to date At baseline, we assessed habitual dietary intake, conducted physical examinations (measuring, eg, anthropometrics, body composition, blood pressure, pulse wave velocity, advanced glycation end product accumulation, cognitive performance), collected blood and 24-hour urine and administered a variety of validated demographic, health and lifestyle questionnaires. Participants had a mean BMI of $26.0 \pm 4.2 \mathrm{~kg} / \mathrm{m}^{2}$, were mostly highly educated $(63 \%)$, married or having a registered partnership $(72 \%)$ and having a paid job (72\%). Estimated daily energy and macronutrient intakes (mean \pm SD) were $8581 \pm 2531 \mathrm{~kJ}, 15 \pm 2$ energy (en\%) of protein, $43 \pm 6$ en $\%$ of carbohydrates, $36 \pm 5$ en $\%$ of fat and $11 \pm 13 \mathrm{~g}$ of alcohol. Mean systolic blood pressure was $126 \pm 15 \mathrm{~mm} \mathrm{Hg}$, total cholesterol $5.3 \pm 1.1 \mathrm{mmol} / \mathrm{L}$ and haemoglobin A1c $36 \pm 5 \mathrm{mmol} / \mathrm{mol}$. A total of $24 \%$ of the participants reported to be diagnosed with hypertension, $18 \%$ with hypercholesterolaemia and $4 \%$ with diabetes mellitus. All measurements were repeated after 1 and 2 years of followup.

Future plans We endeavour to continue measurements on the long-term. Moreover, dietary assessment methods used in the NQplus study will be extensively validated, that is, Food Frequency Questionnaires, 24-hour recalls and urinary and blood biomarkers of exposure. As such, the NQplus study will provide a unique opportunity to study many cross-sectional and longitudinal associations between diet and cardiometabolic health outcomes using the best dietary assessment methods available so far.

\section{INTRODUCTION}

Globally, more than half a billion adults aged $\geq 20$ years are classified as being
Strengths and limitations of this study

- A unique asset of this study is the extensive quantity of dietary data collected, including Food Frequency Questionnaires, multiple 24-hour recalls and nutritional biomarkers.

- The wide range of cardiometabolic factors and ageing-related health outcomes measured allow the exploration of a broad variety of associations between diet and human health.

- Nutrition Questionnaires plus (NQplus) participants are higher educated, have a higher body mass index and less often smoke than the general Dutch population. Therefore, the NQplus study population does not fully represent the general Dutch population.

- Further expansion of the database is possible using stored frozen blood and urine samples. Moreover, participants can still be contacted to fill-out newly developed questionnaires.

obese (body mass index (BMI) $\geq 30 \mathrm{~kg}$ / $\mathrm{m}^{2}$ ) according to WHO. ${ }^{1}$ In addition, the prevalences of hypertension (systolic blood pressure $140+$ and/or diastolic blood pressure $90+$ or using antihypertensive medication), hypercholesterolaemia (total cholesterol $\geq 5.0 \mathrm{mmol} / \mathrm{L}$ ) and hyperglycaemia (fasting plasma glucose value $\geq 7.0 \mathrm{mmol} / \mathrm{L}$ ) among the adult population have been estimated to be around $40 \%{ }^{2}$ $39 \%^{3}$ and $9 \%$, respectively. ${ }^{4}$ As all these factors are known to adversely affect cardiometabolic health, attempts to lower these prevalences should be encouraged. Lifestyle changes might help to achieve this goal and dietary changes may play an important role in this.

Unfortunately, it is not that easy to examine the impact of diet on human health since dietary assessment methods (eg, duplicate 24-hour recalls and Food Frequency Questionnaires (FFQs)) are often suboptimal to measure habitual dietary intake. Duplicate 
24-hour recalls are often not sufficient to assess episodically consumed foods, micronutrients and trace elements as they can be easily missed and as such result in misclassification. For larger studies, FFQs are often the method of choice. However, also FFQs are susceptible to bias, for instance, due to imprecise assessment of portion sizes, errors in food composition tables and the large variation in obtainable foods. Ideally, the validity of an FFQ is examined before diet-health associations are explored, but time and budget are often limiting factors in this process. To reduce the costs and time burden associated with validation studies, we initiated the National Dietary Assessment Reference Database (NDARD) project. ${ }^{5}$ In order to establish the NDARD database, we included 2048 participants providing us with dietary data collected by means of FFQs, repeated 24-hour recalls, as well as urinary/ blood biomarkers. As the questions in Dutch FFQs are generally linked to the food items in the national food composition table, this database allows the validation of existing dietary assessment methods and the development of new dietary assessment methods in a more cost and time effective manner. Therefore, it is expected that the FFQs generated with the use of this new database will provide more accurate dietary data than the FFQs that are currently used.

Given the unique nature of the dietary data collected in view of the NDARD project, we decided to expand the NDARD database by collecting extensive data on participant characteristics, including cross-sectional and longitudinal data on demographics, lifestyle, medical history and (cardiometabolic) health outcomes: the Nutrition Questionnaires plus (NQplus) study. This study provides the opportunity to explore a large number of interesting research questions related to diet and (cardiometabolic) health outcomes using the best dietary intake assessment methods available so far. Associations that can be studied using NQplus data include the potential role of polyphenol intake in relation to blood pressure and arterial stiffness, ${ }^{6} \mathrm{Na} / \mathrm{K}$ excretion in relation to blood pressure, arterial stiffness and metabolic syndrome, ${ }^{7}$ associations between dietary lignans and serum lipids, ${ }^{8}$ associations between meal timing and metabolic health as well as the association between vitamin $\mathrm{D}$, glucose intolerance and cognition. ${ }^{9}$

Given the variety of measurements conducted in view of the NQplus study, the purpose of this article is to provide an overview of the: 1) study design and 2) baseline characteristics of the study population.

\section{COHORT DESCRIPTION Participants}

The NQplus study is a prospective cohort study, primarily conducted among Caucasian Dutch adults aged 20-70 years living in the central part of the Netherlands (ie, Wageningen and vicinity), initiated as an add-on study to the NDARD project. ${ }^{5}$ The NQplus study aimed to recruit 1750 men and women that were able to speak and write Dutch and competent to make their own decisions. Recruitment started in June 2011 and was completed in February 2013. During this period, 2048 men and women were included in the study (figure 1). Baseline measurements included the assessment of habitual dietary intake by an FFQ and repeated 24-hour recalls; physical examinations including measurements of anthropometrics, body composition, blood pressure, pulse wave velocity, advanced glycation end product (AGE) accumulation by skin autofluorescence and cognitive performance; blood sampling; 24-hour urine collection and a variety of validated health and lifestyle questionnaires completed online using the open-source survey tool Limesurvey (LimeSurvey Project Team/Carsten Schmitz, Hamburg, Germany) (table 1). All measurements were repeated at 1 and 2 years of follow-up and performed according to a standardised protocol by trained research assistants. All participants gave written informed consent before commencement of the study.

\section{Blood collection}

Fasting blood samples were collected in the morning at hospital Gelderse Vallei (Ede) or hospital Rijnstate

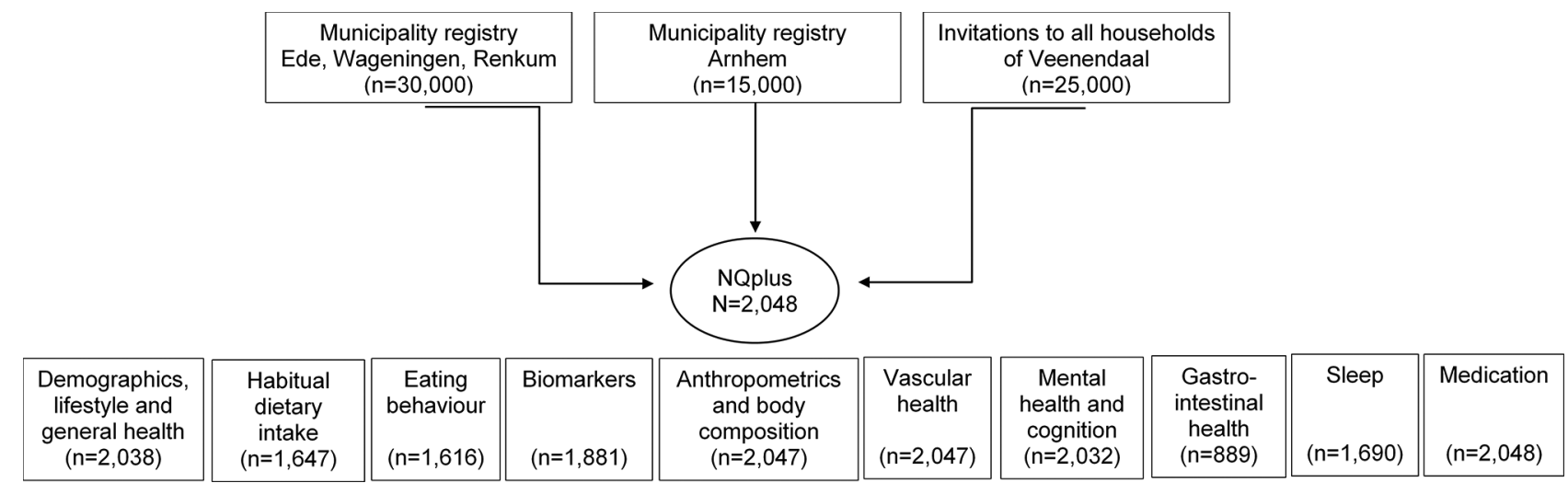

Figure 1 Study flow of the Nutrition Questionnaires plus (NQplus) study. Please note that the n's given for the demographic variables, dietary intake variables and health outcomes are based on a key variable with the most observations within that specific group. 
Table 1 Overview of the measurements in the NQplus study

\begin{tabular}{|c|c|c|}
\hline Domain & Method(s) & Main parameters \\
\hline $\begin{array}{l}\text { Demographics, } \\
\text { lifestyle and general } \\
\text { health }\end{array}$ & General questionnaire & $\begin{array}{l}\text { Age, sex, postal code, birth country of participant and his/her father } \\
\text { and mother, marital status, household composition, educational } \\
\text { level, work situation, smoking habits, medical history regarding } \\
\text { allergies, cancer, diabetes mellitus, cardiovascular health, renal health, } \\
\text { thyroid disorders, eyesight, hearing problems, dental problems, } \\
\text { gastrointestinal health, incontinence, epilepsy, women's health, } \\
\text { whether a participant was breast fed or not, birth weight, sunlight } \\
\text { exposure, etc. }\end{array}$ \\
\hline
\end{tabular}

Short QUestionnaire to ASsess

Health enhancing physical activity/Activity Questionnaire for Adults and Adolescents

\begin{tabular}{ll}
$\begin{array}{l}\text { Habitual dietary } \\
\text { intake }\end{array}$ & FFQs and 24-hour recalls \\
\hline Eating behaviour & $\begin{array}{l}\text { Dutch Eating Behaviour } \\
\text { Questionnaire } \\
\text { Food Choice Questionnaire }\end{array}$ \\
& Food Neophobia Scale \\
& Eating rate question \\
& $\begin{array}{l}\text { Questionnaire developed by } \\
\text { Hooft van Huysduynen and } \\
\text { colleagues } \\
\text { Questionnaire by research } \\
\text { institute Wageningen Economic } \\
\text { Research }\end{array}$
\end{tabular}

$\begin{array}{ll}\text { Biomarkers } & \text { Plasma } \\ & \text { Serum }\end{array}$

Whole blood

$\begin{array}{ll}\text { Anthropometrics } & \text { Urine } \\ & \begin{array}{l}\text { Stadiometer } \\ \text { Digital weighing scale }\end{array} \\ & \begin{array}{l}\text { Measuring tape } \\ \text { Body composition }\end{array} \\ \begin{array}{l}\text { DXA or Tanita body composition } \\ \text { analyser }\end{array}\end{array}$

Body weight Questionnaire

\section{Advanced glycation AGE-Reader} end products

Vascular Digital blood pressure monitor

measurements
Questionnaire assessing the time being physically active, eg, sports, domestic activities, leisure time activities, activities related to homework travelling, resulting in three overall scores, including the total activity time (min), total activity score taking into account duration and intensity and a dichotomous variable indicating whether a participant met the national physical activity guideline of being physically activity for at least 30 min for 5 or more days per week.

Intake levels of macronutrients, micronutrients, trace elements, foods, food groups and dietary patterns.

Questionnaire resulting in three main scores, including an emotional eating score, restrained eating score and external eating score.

Nine factors that may influence our daily dietary choices, ie, health, mood, convenience, sensory appeal, natural content, price, weight control, familiarity and ethical concern.

Questionnaire resulting in a total food neophobia score.

Eating rate judged as very slow, slow, average, fast or very fast.

Parameters on purchase and cooking habits, eating behaviour during dinner, presence/access to (un)healthy foods, knowledge/skills to make healthy food choices, etc.

Three items covering general statements; 13 items covering time, location and company during meals; 18 items covering sweet snack consumption; 7 items covering intentions towards consumption of sweet snacks; 4 items covering meat consumption and 15 items covering intentions towards consumption of meat and meat substitutes.

Total cholesterol, LDL cholesterol, HDL cholesterol, glucose.

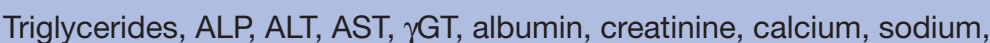
potassium, phosphate, urea, uric acid.

$\mathrm{HbA1c}, \mathrm{Hb}, \mathrm{Ht}$, thrombocytes, erythrocytes, leucocytes, lymphocytes, monocytes, eosinophils, basophils, neutrophils.

PABA, potassium, sodium, creatinine, nitrogen.

Height.

Weight.

Waist and hip circumference.

Total fat mass, lean body mass, body fat percentage and bone mineral density.

Opinion on own body weight, desire to lose weight, currently dieting, dieting frequency, weight at age 18 , weight at age 20 , highest weight in past 5 years, lowest weight in past 5 years and unwanted weight loss.

Skin autofluorescence and skin reflection.

Systolic and diastolic blood pressure.

Applanation tonometry

Augmentation index and resting heart rate. 
Table 1 Continued

\begin{tabular}{|c|c|c|}
\hline Domain & Method(s) & Main parameters \\
\hline \multirow{3}{*}{$\begin{array}{l}\text { Cognitive } \\
\text { performance }\end{array}$} & Symbol Digit Modalities Test & Number of encoded symbols. \\
\hline & Letter Fluency Test & Average number of generated words. \\
\hline & Story Recall & Number of correct items, direct and postponed. \\
\hline \multirow[t]{11}{*}{ Mental well-being } & Rosenberg Self-Esteem Scale & 10-item scale resulting in a total self-esteem score. \\
\hline & Brief Self-Control Scale & 13-item scale resulting in a total trait self-control score. \\
\hline & $\begin{array}{l}\text { Mindful Attention Awareness } \\
\text { Scale }\end{array}$ & 15-item scale resulting in a total mindful attention awareness score. \\
\hline & $\begin{array}{l}\text { Consideration of Future } \\
\text { Consequences Scale }\end{array}$ & $\begin{array}{l}\text { 12-item scale resulting in a total score indicating the extent to which } \\
\text { people emphasise short-term or long-term consequences. }\end{array}$ \\
\hline & Sense of Coherence & $\begin{array}{l}\text { 13-item scale covering comprehensibility, manageability and } \\
\text { meaningfulness. }\end{array}$ \\
\hline & Perceived Stress Scale- 4 & $\begin{array}{l}\text { 4-item scale questioning feelings and thoughts during the past } 2 \text { weeks } \\
\text { resulting in a total stress score. }\end{array}$ \\
\hline & Long-term Difficulties Inventory & $\begin{array}{l}\text { 12-item scale resulting in a total score of chronic stress due to eg, } \\
\text { home, work, relationships, leisure activities, finances, health, school } \\
\text { and religion. }\end{array}$ \\
\hline & $\begin{array}{l}\text { Center for Epidemiological } \\
\text { Studies Depression Scale }\end{array}$ & $\begin{array}{l}\text { 20-item scale asking for depression-related symptoms, eg, insomnia, } \\
\text { loss of appetite and loneliness, resulting in a total depression score. }\end{array}$ \\
\hline & $\begin{array}{l}\text { Short Form } 36 \text {-item Health } \\
\text { Survey }\end{array}$ & $\begin{array}{l}\text { 36-item health-related quality of life questionnaire evaluating eight } \\
\text { elements: physical functioning, limitations due to physical health, } \\
\text { bodily pain, general health, vitality, social functioning, limitations due to } \\
\text { emotional health and mental health. }\end{array}$ \\
\hline & $\begin{array}{l}\text { EuroQol Group EQ-5D Health } \\
\text { Questionnaire }\end{array}$ & $\begin{array}{l}\text { 5-item questionnaire measuring generic health status (mobility, } \\
\text { self-care, usual activities, pain/discomfort and anxiety/depression) } \\
\text { supplemented with a visual analogue scale evaluating overall health } \\
\text { status. }\end{array}$ \\
\hline & $\begin{array}{l}\text { Social Production Function } \\
\text { Instrument for the Level of Well- } \\
\text { being }\end{array}$ & $\begin{array}{l}\text { 9-item questionnaire covering affection, behavioural confirmation, } \\
\text { status, comfort and stimulation. }\end{array}$ \\
\hline $\begin{array}{l}\text { Gastrointestinal } \\
\text { health }\end{array}$ & $\begin{array}{l}\text { Questionnaire based on Rome III } \\
\text { criteria }\end{array}$ & $\begin{array}{l}\text { Questionnaire including questions related to presence of abdominal } \\
\text { pain (including menstrual pain), obstipation, type of stool, gasification/ } \\
\text { swollen abdomen, having an unpleasant feeling full after a normal meal, } \\
\text { eating difficulties, existence of a burning sensation lower abdomen, } \\
\text { etc. }\end{array}$ \\
\hline $\begin{array}{l}\text { Sleep } \\
\text { characteristics }\end{array}$ & $\begin{array}{l}\text { Munich Chronotype } \\
\text { Questionnaire }\end{array}$ & $\begin{array}{l}\text { 6-item questionnaire providing information on the time from } \\
\text { wakefulness into sleep, wake-up time, sleep duration and mid-point } \\
\text { between time to fall asleep and wake-up time. }\end{array}$ \\
\hline Medication use & $\begin{array}{l}\text { Registered during physical } \\
\text { assessment }\end{array}$ & $\begin{array}{l}\text { Classification according to Anatomical Therapeutic Chemical } \\
\text { classification system. }\end{array}$ \\
\hline
\end{tabular}

FFQ, Food Frequency Questionnaire; AGE, advanced glycation end products; DXA, dual-energy X-ray absorptiometry; LDL, low-density lipoprotein; HDL, high-density lipoprotein; HbA1c, haemoglobin A1c; ALP, alkaline phosphatase; ALT, alanine aminotransferase; AST, aspartate aminotransferase; $\gamma$ GT, gamma-glutamyltranspeptidase; Hb, haemoglobin; $\mathrm{Ht}$, haematocrit; PABA, para-aminobenzoid acid.

(Velp). Samples were analysed in the respective hospital laboratories, which both joined the external quality control programme in the Netherlands (SKML) and used the same methodology and standardised protocols for risk factor assessments. Analyses were performed using Dimension Vista 1500 automated analyser (Siemens, Erlangen, Germany) or Roche Modular P800 chemistry analyser (Roche Diagnostics, Indianapolis, USA), unless specified otherwise. Moreover, DNA was isolated from buffy coats and successfully extracted for 721 participants using a Puregene 5Prime-kit. Currently, these samples are being genotyped with the Illumina OmniExpress chip covering $>90 \%$ of all common variation in the genome. Remaining EDTA plasma $(6 \times 0.5 \mathrm{~mL}+1 \times 1.5 \mathrm{~mL})$, citrate plasma $(5 \times 0.5 \mathrm{~mL})$, serum $(3 \times 0.5 \mathrm{~mL}+2 \times 1 \mathrm{~mL})$ and one buffy coat sample were stored at $-80^{\circ} \mathrm{C}$ in the NQplus biobank for future analysis. 


\section{Urine collection}

Urine was collected during one 24-hour period each year. Participants received verbal and written instructions, 2-3 L containers containing the preservative lithium dihydrogenphosphate $(25 \mathrm{~g})$ and three $80 \mathrm{mg}$ para-aminobenzoid acid (PABA) tablets (PABAcheck, Elsie Widdowson Laboratory, Cambridge, UK) on the day before the urine collection. Urine collection started after the first voiding after waking up and finished after the first voiding after waking up the following day. Voiding times, possible deviations from the protocol (eg, missing urine) and the use of medications and/or nutritional supplements were registered. Subsequently, urine containers were collected at the hospital Gelderse Vallei (Ede) or hospital Rijnstate (Velp), where they were stored at $4^{\circ} \mathrm{C}$ for a maximum of 3 days until transportation to the study centre. At the study centre, the urine containers of each participant were mixed, weighted, aliquoted and stored at $-20^{\circ} \mathrm{C}$ until further analyses. PABA was measured at the Division of Human Nutrition (Wageningen University, the Netherlands) by the High-performance Liquid Chromatography (HPLC) method and used to check completeness of the urine samples. ${ }^{10}$ As PABA is assumed to be excreted almost quantitatively within 24 hours, a recovery of at least $78 \%$ (189.6 mg) of the ingested PABA was considered as a complete urine collection. Urine samples with PABA recoveries below $50 \%$ were treated as incomplete $(n=18)$. PABA recoveries between $50 \%$ and $78 \%$ were proportionally adjusted to $88 \%$ using linear regression equations as recommended $(n=187) .{ }^{11}$ Next to the scheduled urinary analyses at baseline, three 24-hour urine samples of $4.5 \mathrm{~mL}$ each were stored at $-20^{\circ} \mathrm{C}$ in the NQplus biobank for future analyses.

\section{Dietary data collection}

An extensive description of the dietary assessment methods can be found in the NDARD project paper. ${ }^{5}$ In short, FFQs were self-administered and completed online using the open-source survey tool Limesurvey; 24-hour recalls were telephone-based as well as web-based. Telephone-based 24-hour recalls were performed by dieticians who were trained in interviewing skills; using a standardised protocol. Web-based recalls were self-administered using the software programme Compl-eat (www.compleat.nl). ${ }^{12}$ Average daily nutrient intakes were calculated by multiplying the consumption frequency by the portion size and nutrient content in grams as indicated in the most recent Dutch food composition table (2011). The dietary data collected also allow the study of individual food items or food groups as well as dietary patterns, where dietary patterns can be derived a priori (eg, based on the Mediterranean diet score) and a posteriori (eg, using principal component analysis, factor analysis or cluster analysis).

\section{Eating behaviour}

Restrained eating (ie, restraint from the consumption of foods and dieting behaviour), emotional eating (ie, eating when upset or in negative moods) and external eating (ie, eating in response to sight or smell of food) were assessed with the Dutch Eating Behaviour Questionnaire. ${ }^{13}$ Eating behaviour was also assessed by a questionnaire developed by research institute Wageningen Economic Research covering the following five aspects: (1) general statements, (2) time, location and company during meals, (3) sweet snacks consumption, (4) intentions towards consumption of sweet snacks and (5) meat consumption and intentions towards consumption of meat and meat substitutes. Factors related to food choice (ie, health, mood, convenience, sensory appeal, natural content, price, weight control, familiarity and ethical concern) were assessed with the Food Choice Questionnaire. ${ }^{14}$ Food neophobia, that is, the reluctance to eat or avoidance of novel foods, was scored using the Food Neophobia Scale. ${ }^{15}$ Furthermore, eating rate was assessed, scored according to one of five rating categories: very slow, relatively slow, medium, relatively fast, very fast. ${ }^{16}$ Finally, to examine determinants of intake of fruit, vegetables and snacks, participants completed a questionnaire developed by Hooft van Huysduynen and colleagues. Determinants were mainly derived from the Theory of Planned Behaviour ${ }^{17}$ and included questions on intention, attitude, subjective norm and perceived behavioural control. Also determinants such as habit strength ${ }^{1819}$ and home food accessibility ${ }^{20}$ were included in the questionnaire.

\section{Nutritional (recovery) biomarkers}

Total 24-hour urinary nitrogen excretion was determined by the Kjeldahl technique (Foss Kjeltec 2300 analyser). ${ }^{21}$ Urinary sodium and potassium concentrations were measured with an ion-selective electrode on a Roche 917 analyser (Roche Diagnostics). Urinary creatinine was measured at $520 \mathrm{~nm}$ on the Synchron LX20 by the modified Jaffé procedure using a commercial kit. Total 24 hours sodium and potassium excretion were calculated by multiplying total weight of collected urine by sodium or potassium concentration and divided by 0.86 for sodium ${ }^{22}$ and by 0.81 for potassium ${ }^{23}$ (ie, the assumed percentage of intake excreted in urine). Urinary protein was calculated by $6.25 \times($ urinary $\mathrm{n} / 0.81)$, accounting for faecal and skin losses (approximately 19\%). ${ }^{24}$

\section{Anthropometrics}

Prior to measurements, participants were asked to take off their shoes, sweaters and to empty their pockets. Height was measured with a stadiometer (SECA, Germany) to the nearest $0.1 \mathrm{~cm}$. Weight was measured using a digital scale (SECA) to the nearest $0.1 \mathrm{~kg}$. Waist and hip circumference were measured twice using a non-flexible measuring tape (SECA 201) to the nearest $0.5 \mathrm{~cm}$; the average of the two measurements was included in the dataset.

\section{Body composition}

Body composition (ie, total fat mass, lean body mass, body fat percentage) and bone mineral density were 
measured by a dual-energy X-ray absorptiometry (DXA) scan (Lunar prodigy, GE healthcare).$^{25}$ If a participant did not fit the width outline of the scanner, only the right side of the body was scanned and results were mirrored. In a subsample $(\mathrm{n}=199)$, body composition (ie, total fat, lean body mass, fat percentage) were measured using the Tanita body composition analyser (BC418MA, Tanita) instead of DXA.

\section{Advanced glycation end products}

AGEs accumulation was non-invasively measured with an AGE-Reader (DiagnOptics, Groningen, the Netherlands) in the human skin of the inner side of the lower forearm. ${ }^{26}{ }^{27}$ Measurements were repeated three times and averaged.

\section{Vascular measurements}

After 10 min of rest, blood pressure was measured on the left arm, six times with 2 min rest in between, while the participant was in supine position (IntelliSense HEM-907, Omron Healthcare, USA). The first measurement was omitted to acclimatise the participant to the measurements; the second up to the sixth measurement were averaged. Dominant arm and room temperature were recorded. Arterial stiffness was assessed by pulse wave analysis of the radial artery by applanation tonometry (SphygmoCor system, ATcor Medical, Sydney, Australia). A pressure-sensitive probe was placed on the radial artery to generate a pulse pressure wave. Subsequently, the corrected augmentation index (Aix) was estimated by combining the data of the brachial blood pressure measurements, central aortic pressure measurements and heart rate measurements. ${ }^{28-30}$

\section{Fasting blood biomarkers}

Total cholesterol, high-density lipoprotein (HDL)-cholesterol, triglycerides, glucose and creatinine were determined with enzymatic methods. ${ }^{31}$ Low-density lipoprotein (LDL)-cholesterol was calculated with the Friedewald equation. ${ }^{32}$ Catalytic activity concentration of alanine aminotransferase (ALT), aspartate aminotransferase and gamma-glutamyltranspeptidase levels were measured by international federation of clinical chemistry reference procedures at $37^{\circ} \mathrm{C}$. For albumin determinations the bromocresol purple method was used. ${ }^{33}$ Haemoglobin A1c (HbAlc) was determined with HPLC measurement technology using an ADAMS A1c HA-8160 analyser (A. Menarini Diagnostics). Haemoglobin and ha ematocrit were assessed with colorimetric measurements using Advia 2120i Automatic analyser (Siemens) or using Sysmex XNseries (Sysmex, Lincolnshire, USA). Erythrocytes and leucocytes, including monocytes and lymphocytes, were determined with flow cytometry (Advia 2120i automatic analyser, Siemensor Sysmex XNseries). An estimated glomerular filtration rate was calculated using the Modification of Diet in Renal Disease study equation ${ }^{34} 35$ as well as the new Chronic Kidney Disease Epidemiology Collaboration equation. ${ }^{36}$

\section{Cognitive performance}

Cognitive performance was assessed using three standardised neuropsychological paper-pencil tests. The symbol digit modalities test was used to measure information processing speed. ${ }^{3738}$ The story recall, a subtest of the Rivermead Behavioural Memory Tests direct and delayed recall, was used for assessment of everyday memory problems. ${ }^{39}$ Lastly, the verbal fluency test was used to evaluate semantic memory and language production. ${ }^{40}$

\section{Mental well-being}

The Rosenberg Self-Esteem Scale was used to measure global self-worth. ${ }^{41}{ }^{42}$ The Brief Self-Control Scale was used to assess five dimensions of self-control: a general capacity for self-discipline, an inclination towards deliberate or non-impulsive action, a range of healthy habits, self-regulation in service of a work ethic and reliability. ${ }^{43}$ The Social Production Function Instrument for the level of well-being was used to measure levels of affection, behavioural confirmation, status, comfort and stimulation. ${ }^{44}$ Mindfulness was measured with the Mindful Attention Awareness Scale, which includes 15 items to assess the individual differences in the frequency of mindful states over time. ${ }^{45}$ The Consideration of Future Consequences Scale was used to assess to which extent individuals consider the potential distant outcomes of their current behaviours and the extent to which individuals are influenced by these potential outcomes. ${ }^{46}$ The Sense of Coherence questionnaire was used to evaluate the global orientation of life, that is, the feeling that life is comprehensible, manageable and meaningful. ${ }^{47}$ The Perceived Stress Scale-4 was used to assess the degree to which participants judged particular situations as being stressful, by asking about feelings and thoughts in the last month. ${ }^{48} 49$ The Long-term Difficulties Inventory was used to measure different domains of chronic stress. ${ }^{50}$ Current levels of depressive symptomatology were measured by the Centre for Epidemiological Studies Depression Scale. ${ }^{51}$ Finally, the RAND Short Form 36-item Health Survey and the EuroQol Group EQ-5D Health Questionnaire were used to assess quality of life. ${ }^{52}$

\section{Gastrointestinal health}

Functional gastrointestinal health was assessed by a questionnaire that was designed using the Rome III criteria, referring to functional dyspepsia, including postprandial distress syndrome and functional bowel disorders (ie, irritable bowel syndrome, functional bloating, functional constipation, functional diarrhoea and unspecified functional bowel disorders). ${ }^{53} 54$

\section{Sleep characteristics}

With the Munich Chronotype Questionnaire, sleep and activity times were registered. ${ }^{55}$ Questions included: when do you go to bed, how long do you need to fall asleep, when do you wake up? Questions were asked separately for work and free (non-work) days. Main parameters included estimates of sleep duration, sleep onset time (ie, 
bedtime plus sleep latency), rise time and mid-point of sleep.

\section{Demographics, lifestyle and general health}

The general questionnaire included questions about demographics, including birth country, marital status, household composition and education; work history and current work situation; health and history of diseases such as allergies; cancer, diabetes mellitus, cardiovascular health, renal health including surgery, thyroid disorders, eyesight, hearing and dental problems, general disorders and medication use; current body weight and body weight in the past (ie, lowest weight in the past 5 years, highest weight in the past 5 years, weight at age 18 (women) and weight at age $20(\mathrm{men}))$; information specific for women such as pregnancy, menstruation, gynaecological surgery, contraception use; birth weight and breast feeding; day time spending such as volunteering, informal care and screen time; living environment; social activities; current and previous smoking habits such as the amount smoked, age at start and end of smoking periods and type of tobacco smoked and information on passive smoking. Most of these questions were derived from the general questionnaires of the LifeLines study. ${ }^{56}$ Participants with no education or primary or lower vocational education as highest completed education were classified as having a low education level. Participants who completed lower secondary or intermediate vocational education were classified as having an intermediate education level and participants with a high education level were those who completed higher secondary education, higher vocational education or university. Never smokers did not smoke during the past month and never smoked for a full year. Participants who smoked during the past month or ever smoked for a full year and did not stop smoking were classified as current smokers. Participants who ever smoked for a full year, but did not smoke in the past month and quit smoking were classified as former smokers. Information about the participants' usual physical activity over the past 4 weeks was obtained using two validated questionnaires: the Short QUestionnaire to ASsess Health enhancing physical activity (SQUASH) ${ }^{57}$ and the Activity Questionnaire for Adults and Adolescents (AQuAA). ${ }^{58}$ The SQUASH contains questions evaluating the participants' compliance to the Dutch physical activity guidelines, specifically, a physical activity pattern including at least $30 \mathrm{~min}$ of moderate intensity physical activity on $\geq 5$ days / week. ${ }^{57}$ The AQuAA is based on the SQUASH questionnaire, but it also includes questions on light intensity activities and sedentary behaviours and questions on age-specific examples of activities. In addition, questions in the AQuAA questionnaire relate to activities performed in the previous 7 days instead of an average week. The main outcomes are a total physical activity score and time spent on sedentary, light, moderate and vigorous intensity activities in minutes per week. ${ }^{58}$ Medication use was registered during the physical examination. Type of medication was classified according to the Anatomical Therapeutic Chemical classification system.

\section{Patient and public involvement}

Many people have one or more cardiometabolic conditions. By studying a group of Dutch adults, the NQplus study aims to identify lifestyle/dietary factors that may contribute to the prevention of these cardiometabolic conditions. These Dutch adults were recruited via: 1) random sampling from the municipality registries of Ede, Wageningen, Renkum $(\mathrm{n}=30000)$ and Arnhem $(\mathrm{n}=15000)$ by sending invitation letters; and 2) sending invitation letters to all households of Veenendaal $(n=25000)$; participants were not actively involved in the recruitment process or design of the study. Participants are informed about the study results through newsletters and information meetings. Moreover, each participant received a letter with his/her personal results as obtained during the physical examinations.

\section{Baseline characteristics}

In total, 2048 men (52\%) and women (48\%) entered the NQplus study (table 2). Participants were aged $51 \pm 12$ years, mostly highly educated $(63 \%)$, being married or having a registered partnership (72\%) and having a paid job (72\%). Estimated daily energy and macronutrient intakes (mean $\pm \mathrm{SD})$ of the NQplus population were comparable to the intakes in the general Dutch population as estimated by the Dutch National Food Consumption Survey. Specifically being $8581 \pm 2531 \mathrm{~kJ}, 15 \pm 2$ en $\%$ of protein, $43 \pm 6$ en $\%$ of carbohydrates, $36 \pm 5$ en\% of fat and $11 \pm 13 \mathrm{~g}$ of alcohol. Table 3 gives an overview of the cardiometabolic characteristics of the population. Participants had a mean BMI of $26.0 \pm 4.2 \mathrm{~kg} / \mathrm{m}^{2}$ (men: $26.5 \pm 3.7$; women: $25.5 \pm 4.6 \mathrm{~kg} / \mathrm{m}^{2}$ ), waist circumference of $92 \pm 13 \mathrm{~cm}$ (men: $97 \pm 11$; women: $86 \pm 12 \mathrm{~cm}$ ) and a waist-to-hip ratio of $0.88 \pm 0.09$ (men: $0.93 \pm 0.07$; women: $0.82 \pm 0.07$ ). Mean $( \pm \mathrm{SD})$ diastolic blood pressure was $74 \pm 10 \mathrm{~mm} \mathrm{Hg}$ (men: $76 \pm 10$; women: $72 \pm 10 \mathrm{~mm} \mathrm{Hg}$ ), systolic blood pressure $126 \pm 15 \mathrm{~mm} \mathrm{Hg}$ (men: 131 \pm 14 ; women: $119 \pm 15 \mathrm{~mm} \mathrm{Hg}$ ), total cholesterol $5.3 \pm 1.1 \mathrm{mmol} / \mathrm{L}$ (men: $5.3 \pm 10$; women: $5.4 \pm 1.1 \mathrm{mmol} / \mathrm{L}), \quad$ LDL cholesterol $3.2 \pm 0.9 \mathrm{mmol} / \mathrm{L}$ (men: $3.3 \pm 0.9$; women: $3.2 \pm 0.9 \mathrm{mmol} / \mathrm{L}$ ), HDL cholesterol $1.6 \pm 0.5 \mathrm{mmol} / \mathrm{L}$ (men: $1.4 \pm 0.4$; women: $1.8 \pm 0.5 \mathrm{mmol} / \mathrm{L})$, fasting triglycerides $1.2 \pm 0.8 \mathrm{mmol} / \mathrm{L}$ (men: $1.4 \pm 1.0$; women: $1.1 \pm 0.6 \mathrm{mmol} / \mathrm{L}), \quad \mathrm{HbA1c}$ $36 \pm 5 \mathrm{mmol} / \mathrm{mol}$ (men: $36.5 \pm 4.4$; women: $35.8 \pm 5.0 \mathrm{mmol} /$ $\mathrm{mol}$ ) and fasting glucose $5.5 \pm 0.9 \mathrm{mmol} / \mathrm{L}$ (men: $5.6 \pm 0.9$; women: $5.4 \pm 0.9 \mathrm{mmol} / \mathrm{L}$ ). Stratification of aforementioned cardiometabolic outcomes according to educational level did not suggest major differences between those with a low, intermediate or high educational level (figure 2). However, one-way analysis of variance did show a significant $(\mathrm{p}<0.05)$ lower BMI and HbA1c among those with a high educational level, compared with those with a low or intermediate educational level. In total, $24 \%$ of the participants reported to be diagnosed with hypertension, $18 \%$ with hypercholesterolaemia and $4 \%$ with 
Table 2 Baseline characteristics of the NQplus participants*

\begin{tabular}{|c|c|c|c|c|}
\hline Characteristic & $\mathbf{N}$ & All & Men & Women \\
\hline Men, n (\%) & 2048 & $1063(52)$ & $1063(100)$ & $0(0)$ \\
\hline Age, years & 2045 & $51 \pm 12$ & $54 \pm 12$ & $49 \pm 13$ \\
\hline Education level, $n(\%)$ & 2038 & & & \\
\hline Low & & $146(7)$ & $89(9)$ & $57(6)$ \\
\hline Intermediate & & $617(30)$ & $301(28)$ & $316(32)$ \\
\hline High & & $1275(63)$ & $670(63)$ & $605(62)$ \\
\hline Marital status, $\mathrm{n}(\%)$ & 1957 & & & \\
\hline Married/registered partnership & & $1410(72)$ & $795(79)$ & $615(65)$ \\
\hline Cohabiting & & $198(10)$ & $89(9)$ & $109(11)$ \\
\hline Serious relationship, not cohabiting & & $59(3)$ & $29(3)$ & $30(3)$ \\
\hline Single & & $176(9)$ & $52(5)$ & $124(13)$ \\
\hline Widowed & & $34(2)$ & $5(1)$ & $29(3)$ \\
\hline Divorced & & $80(4)$ & $35(3)$ & $45(5)$ \\
\hline Paid job currently, n (\%) & 1878 & & & \\
\hline Yes & & $1354(72)$ & $699(71)$ & $655(73)$ \\
\hline No & & $524(28)$ & $281(29)$ & $243(27)$ \\
\hline Geographical area, n (\%) & 2048 & & & \\
\hline Ede, Wageningen, Renkum & & $928(45)$ & $334(32)$ & $594(60)$ \\
\hline Arnhem & & $228(11)$ & $79(7)$ & $149(15)$ \\
\hline Veenendaal & & $891(44)$ & $650(61)$ & $241(25)$ \\
\hline Macronutrient intake & 1647 & & & \\
\hline Total energy, kJ/day & & $8581 \pm 2531$ & $9389 \pm 2640$ & $7707 \pm 2088$ \\
\hline Total protein, en $\%$ & & $15 \pm 2$ & $15 \pm 2$ & $15 \pm 2$ \\
\hline Total carbohydrates, en\% & & $43 \pm 6$ & $43 \pm 6$ & $43 \pm 6$ \\
\hline Total fat, en\% & & $36 \pm 5$ & $36 \pm 5$ & $36 \pm 6$ \\
\hline Alcohol, g & & $11 \pm 13$ & $15 \pm 15$ & $7 \pm 9$ \\
\hline
\end{tabular}

*Shown are mean \pm SD or $\mathrm{n}(\%)$. Some of the general characteristics have already been published as part of the paper on the National Dietary Assessment Reference Database project.

NQplus, Nutrition Questionnaires plus.

diabetes mellitus; of these, $57 \%, 57 \%$ and $94 \%$ participants reported to receive medication and/or dietary treatment for these conditions, respectively. In total, 1113 participants completed $3.6 \pm 1.6$ phone-based recalls and 1783 participants completed $5.2 \pm 2.5$ web-based recalls. The general FFQ was completed by $1647(80 \%)$ of the participants.

\section{Findings to date}

As already mentioned before, the NQplus study was principally designed to study associations of nutrients, foods and dietary patterns with cardiometabolic health outcomes. Sluik et $a l^{59}$ already explored associations between alcoholic beverage preference and various cardiometabolic and lifestyle factors within this population. Wine was shown to be the most popular alcoholic beverage consumed (43\%) followed by beer $(13 \%)$ and spirits (4\%); $25 \%$ of the population did not have a specific preference and $15 \%$ did not consume alcoholic beverages. After full adjustment for covariates, men with a preference for wine were less likely to be overweight than men with a preference for other alcoholic drinks; no such association was observed among women. Wine consumers had the highest HDL cholesterol and lowest HbAlc concentrations, whereas those favouring beer had the highest systolic blood pressure, triglyceride, ALT and gamma- glutamyltranspeptidase levels and the lowest scores for the 'Salads' pattern as derived by principal component analysis on 32 energy-adjusted food groups. Participants with a preference for spirits or no specific preference were more likely to have a 'potatoes and sweets' pattern. Moreover, compared with non-alcohol consumers, participants consuming alcohol had higher scores for the 'meat' pattern and lower scores for the 'bread' pattern. ${ }^{59}$ Furthermore, the NQplus dataset revealed significant associations between the intake of coffee and AGEs as measured with skin autofluorescence; stratified analyses for sex furthermore showed an association between full-fat dairy intake and AGE levels among 
Table 3 Selected cardiometabolic factors of the NQplus participants*

\begin{tabular}{|c|c|c|c|c|}
\hline Risk factor & $\mathbf{N}$ & All & Men & Women \\
\hline Smoking status, $\mathrm{n}(\%)$ & 1541 & & & \\
\hline Current & & $140(9)$ & $82(10)$ & $58(8)$ \\
\hline Former & & $613(40)$ & $366(45)$ & 247 (34) \\
\hline Never & & $788(51)$ & $363(45)$ & $425(58)$ \\
\hline $\mathrm{BMI}, \mathrm{kg} / \mathrm{m}^{2}$ & 2047 & $26.0 \pm 4.2$ & $26.5 \pm 3.7$ & $25.5 \pm 4.6$ \\
\hline Waist circumference, $\mathrm{cm}$ & 2044 & $92 \pm 13$ & $97 \pm 11$ & $86 \pm 12$ \\
\hline Hip circumference, $\mathrm{cm}$ & 2046 & $104 \pm 8$ & $104 \pm 7$ & $104 \pm 9$ \\
\hline Waist-to-hip ratio & 2044 & $0.88 \pm 0.09$ & $0.93 \pm 0.07$ & $0.82 \pm 0.07$ \\
\hline Diastolic blood pressure, $\mathrm{mm} \mathrm{Hg}$ & 2047 & $74 \pm 10$ & $76 \pm 10$ & $72 \pm 10$ \\
\hline Systolic blood pressure, $\mathrm{mm} \mathrm{Hg}$ & 2047 & $126 \pm 15$ & $131 \pm 14$ & $119 \pm 15$ \\
\hline Total cholesterol, mmol/L & 1881 & $5.3 \pm 1.1$ & $5.3 \pm 1.0$ & $5.4 \pm 1.1$ \\
\hline LDL cholesterol, mmol/L & 1878 & $3.2 \pm 0.9$ & $3.3 \pm 0.9$ & $3.2 \pm 0.9$ \\
\hline HDL cholesterol, mmol/L & 1880 & $1.6 \pm 0.5$ & $1.4 \pm 0.4$ & $1.8 \pm 0.5$ \\
\hline Fasting triglycerides, $\mathrm{mmol} / \mathrm{L}$ & 1881 & $1.2 \pm 0.8$ & $1.4 \pm 1.0$ & $1.1 \pm 0.6$ \\
\hline $\mathrm{HbA} 1 \mathrm{c}, \mathrm{mmol} / \mathrm{mol}$ & 1871 & $36 \pm 5$ & $37 \pm 4$ & $36 \pm 5$ \\
\hline Fasting glucose, $\mathrm{mmol} / \mathrm{L}$ & 1879 & $5.5 \pm 0.9$ & $5.6 \pm 0.9$ & $5.4 \pm 0.9$ \\
\hline Alanine aminotransferase, $\mathrm{U} / \mathrm{L}$ & 1879 & $27.0 \pm 14.9$ & $31.3 \pm 15.2$ & $22.5 \pm 13.2$ \\
\hline Aspartate aminotransferase, U/L & 1878 & $22.8 \pm 8.5$ & $23.6 \pm 8.7$ & $21.9 \pm 8.3$ \\
\hline Gamma-glutamyltransferase, U/L & 1881 & $24.8 \pm 25.2$ & $29.7 \pm 28.8$ & $19.8 \pm 19.6$ \\
\hline Glomerular filtration rate, $\mathrm{mL} / \mathrm{min} / 1.73 \mathrm{~m}^{2}$ & 1881 & $89.9 \pm 14.6$ & $88.4 \pm 14.3$ & $91.2 \pm 14.8$ \\
\hline \multicolumn{5}{|l|}{ Disease history, $\mathrm{n}(\%)$} \\
\hline Myocardial infarction & 1945 & $34(2)$ & $29(3)$ & $5(1)$ \\
\hline Stroke & 1946 & $19(1)$ & $13(1)$ & $6(1)$ \\
\hline Diabetes mellitus & 1955 & $69(4)$ & $49(5)$ & $20(2)$ \\
\hline Cancer & 1949 & $103(5)$ & $46(5)$ & $57(6)$ \\
\hline Self-perceived health, $n$ (\%) & 1686 & & & \\
\hline Excellent & & $186(11)$ & 105 (13) & 81 (10) \\
\hline Very good & & $521(31)$ & $258(31)$ & $263(31)$ \\
\hline Good & & $857(51)$ & $430(51)$ & $427(50)$ \\
\hline Fair & & $115(7)$ & $46(5)$ & $69(8)$ \\
\hline Poor & & $7(0)$ & $1(0)$ & $6(1)$ \\
\hline
\end{tabular}

${ }^{*}$ Shown are mean \pm SD or $\mathrm{n}(\%)$. Some of the data presented in this table have already been published as part of the paper on the National Dietary Assessment Reference Database project.

NQplus, Nutrition Questionnaires plus.

men. ${ }^{60}$ van Lee et al used the NQplus database to evaluate the performance of the 34-item screener to assess the Dutch Healthy Diet (DHD) index by comparing it with nutrient intakes as estimated by a 180 -item FFQ as well as levels of cardiometabolic risk factors. The DHD index showed an acceptable correlation with the 180-item FFQ; no associations were observed between the DHD index and the cardiometabolic factors under study. ${ }^{61}$

\section{Strengths and limitations}

A unique feature of the NQplus study is its dietary data collection approach, including the use of various FFQs, multiple phone-based and web-based 24-hour recalls, as well as biochemical markers. Most large-scale observational studies only use a single FFQ to assess dietary intake. The dietary assessment approach used in the NQplus study is expected to provide more accurate estimates of habitual dietary intake than dietary intake estimates based on one single dietary assessment method. Moreover, given the assessment of a wide range of demographic, lifestyle, cardiometabolic factors, other ageing-related health outcomes and determinants of dietary intake, this cohort allows the exploration of a broad variety of associations between diet and human health as well as adjustment for many potential covariates.

\section{Generalisability}

When comparing our macronutrient intake data with macronutrient intake data of the Dutch National Food 

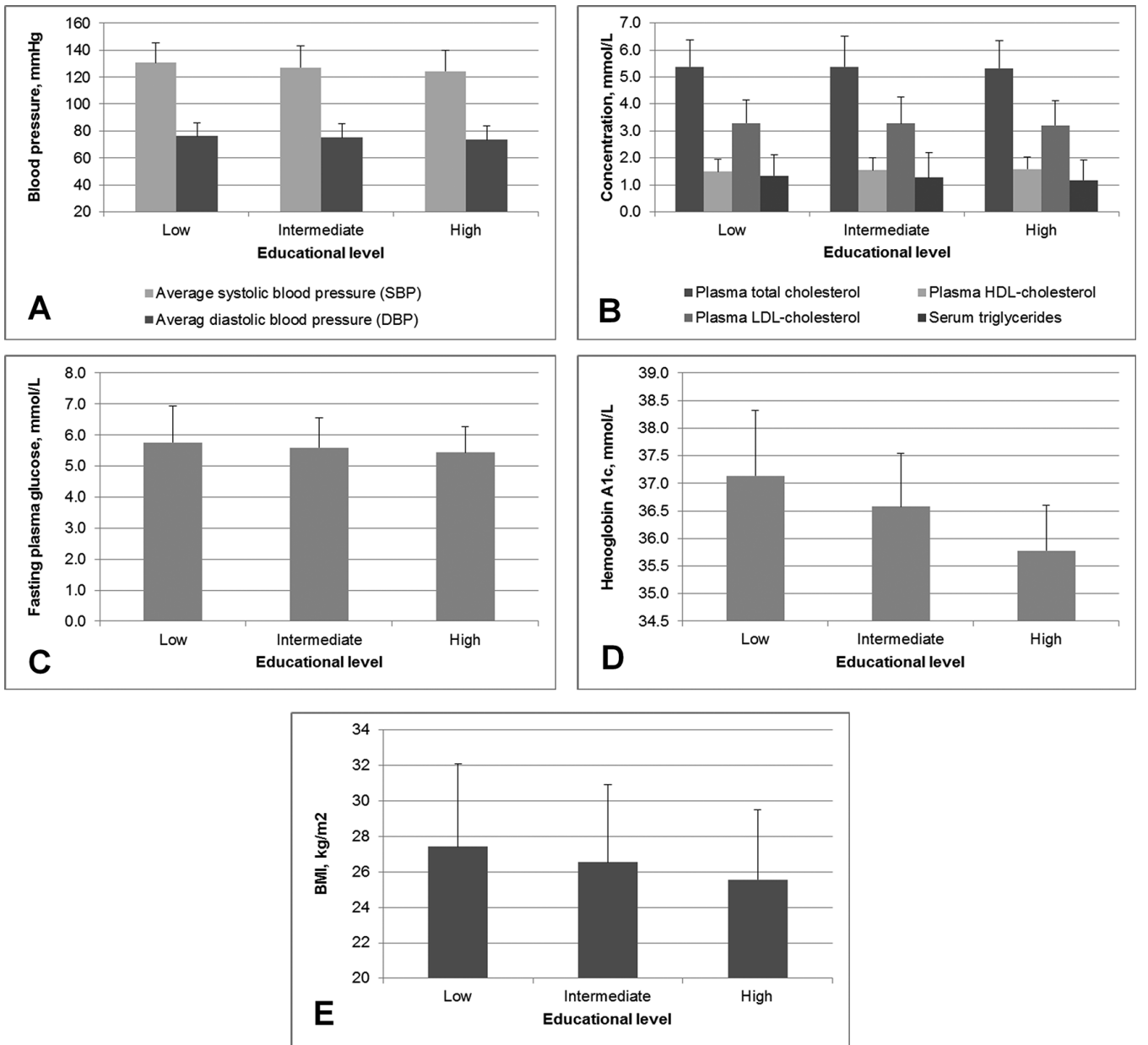

Figure 2 Cardiometabolic risk markers by educational level. (A) Blood pressure, (B) serum/plasma fatty acid concentrations, (C) fasting plasma glucose, (D) Haemoglobin A1C and (E) body mass index (BMI). HDL, high-density lipoprotein; LDL, lowdensity lipoprotein.

Consumption Survey-for women 15 vs 16 en\% of protein, 43 vs 45 en\% of carbohydrates and 36 vs $34 \mathrm{en} \%$ of fat-we can conclude that the NQplus population is largely comparable to the Dutch population with respect to the dietary intake. Comparison of several general characteristics of the NQplus study with data of 2014 of Statistics Netherlands shows that the proportion of men and women and marital status of the NQplus population is also comparable with the general Dutch population. The amount of alcohol consumed was quite similar between the general Dutch population (ie, 1.4 glasses per person) and the NQplus population (ie, 1.1 glasses per person) as well. However, $49 \%$ of the general Dutch population was overweight $\left(\mathrm{BMI} \geq 25 \mathrm{~kg} / \mathrm{m}^{2}\right)$. With $55 \%$, the percentage of participants with overweight was somewhat higher in the NQplus population. Moreover, where 26\% of the general Dutch population aged $\geq 18$ years smokes, only $9 \%$ of the NQplus participants indicated to smoke. Furthermore, the NQplus population reported a substantially higher educational level than the general Dutch population. Specifically, $63 \%$ of the NQplus population completed higher secondary education, higher vocational education or university, which was around $27 \%$ in the general Dutch population. However, we do not expect that this difference in educational level has major implications for the majority of the aetiologic associations between an exposure and outcome measure that can be studied using the NQplus data. In fact, participants in our population may have been even more thorough and precise in completing the questionnaires and assignments than the general population. Finally, previous data show substantially higher rates of cardiometabolic conditions among non-white populations as compared with populations of white European descent. ${ }^{62}$ As the NQplus population predominantly includes Caucasian men and women, the NQplus data can unfortunately not help to unravel underlying pathways explaining ethnic health inequalities by itself. However, NQplus data can be of value for such studies when included as part of larger international databases, as for instance done by the PreView project (https://preview.ning.com/).

\section{Collaboration}

During the past years, several substudies have commenced within the NQplus population. For instance, a subsample of 92 men and 108 women was recruited to participate in an in-depth assessment of dietary intake, energy expenditure and physical activity. ${ }^{63}$ This subgroup was requested 
to collect duplicate food portions for 2 days, to participate in a doubly labelled water measurement and to wear an accelerometer for 7 days. As these additional measurements can be used in future FFQ calibration studies, these data are expected to contribute to further improvement of currently used dietary assessment techniques and thus lead to more precise nutrient intake measurements. As the project is still ongoing, further expansion of the database is possible. Where desirable, additional biochemical analyses can be performed using stored frozen blood and urine samples. Researchers interested in using (part of) the NQplus data can contact the corresponding author. All proposals will be reviewed on scientific quality and methodology; data will be provided on a fee-for-service basis.

\section{CONCLUSION}

Cardiometabolic conditions are responsible for a substantial part of the total global burden of disease. Identification of modifiable cardiometabolic risk factors is therefore of major importance. Diet is considered to be one of the modifiable risk factors. In the Dutch NQplus study, an extensive body of data is collected on habitual dietary intake, eating behaviour and a variety of health outcomes, predominantly cardiometabolic health outcomes. As such, we believe that the NQplus study offers a unique opportunity to provide insight in potentially modifiable diet-related risk factors for cardiometabolic health and contribute to the implementation of evidence-based nutritional recommendations.

Acknowledgements The authors would like to thank all participants for their valuable contribution and cooperation and the dedicated research staff that was involved in execution of the study. The authors would like to thank the clinical chemists of the Clinical Chemistry Department at Ziekenhuis Gelderse Vallei (Ede, the Netherlands), hospital Rijnstate (Velp, the Netherlands) and the dietetic staff of the Division of Human Nutrition (Wageningen, the Netherlands). Finally, the authors would also like to thank Veiligheids-en Gezondheids Regio Gelderland-midden (Arnhem, the Netherlands) for their help with recruitment.

Contributors AG, JHMdV and EJMF participated in the design of the study. AG, EJMF, LvL and AMvdW coordinated the study and were involved in data collection. LvL, DS, MTS, AMvdW and EMB-B were responsible for data management. EMB-B, LVL and MTS performed statistical analyses and drafted the manuscript. All authors read and approved the final manuscript.

Funding This study was core funded by ZonMw (ZonMw, Grant 91110030). NDARD was furthermore supported by the Wageningen University, Wageningen; add-on funding ZonMW Gezonde Voeding DHD-index (ZonMw, Grant 115100007); add-on lab measurements diabetes by EU PreView (EU,Grant 31 2057); add-on validation of BBMRI FFQ and Maastricht FFQ (Grant BBMRI-NL RP9 and CP2011-38).

Competing interests None declared.

Patient consent Obtained.

Ethics approval The NQplus study was approved by the ethical committee of Wageningen University and Research and was conducted according to the Declaration of Helsinki.

Provenance and peer review Not commissioned; externally peer reviewed.

Data sharing statement Researchers can apply for data and biomaterial by contacting the corresponding author.

Open access This is an open access article distributed in accordance with the Creative Commons Attribution Non Commercial (CC BY-NC 4.0) license, which permits others to distribute, remix, adapt, build upon this work non-commercially, and license their derivative works on different terms, provided the original work is properly cited, appropriate credit is given, any changes made indicated, and the use is non-commercial. See: http://creativecommons.org/licenses/by-nc/4.0/.

\section{REFERENCES}

1. WHO. Global health observatory data: obesity, situations and trends. secondary global health observatory data: obesity, situations and trends. 2015 http://www.who.int/gho/ncd/risk_factors/obesity_text/ en/

2. WHO. Global health observatory data: raised blood pressure, situation and trends. secondary global health observatory data: raised blood pressure, situation and trends. 2015 http://www.who. int/gho/ncd/risk_factors/blood_pressure_prevalence_text/en/

3. WHO. Global health observatory data: raised cholesterol, situation and trends secondary global health observatory data: raised cholesterol, situation and trends. 2015 http://www.who.int/gho/ncd/ risk_factors/cholesterol_text/en/

4. WHO. Global health observatory data: raised fasting blood glucose, situation and trends. secondary global health observatory data: raised fasting blood glucose, situation and trends. $2015 \mathrm{http}: / / \mathrm{www}$. who.int/gho/ncd/risk_factors/blood_glucose_text/en/

5. Brouwer-Brolsma EM, Streppel MT, van Lee L, et al. A National Dietary Assessment Reference Database (NDARD) for the Dutch Population: Rationale behind the Design. Nutrients 2017;9:1136.

6. Buijsse B, Feskens EJ, Kok FJ, et al. Cocoa intake, blood pressure, and cardiovascular mortality: the Zutphen Elderly Study. Arch Intern Med 2006;166:411-7.

7. Todd AS, Macginley RJ, Schollum JB, et al. Dietary salt loading impairs arterial vascular reactivity. Am J Clin Nutr 2010;91:557-64.

8. Bassett CM, Rodriguez-Leyva D, Pierce GN. Experimental and clinical research findings on the cardiovascular benefits of consuming flaxseed. Appl Physiol Nutr Metab 2009;34:965-74.

9. Brouwer-Brolsma EM, Dhonukshe-Rutten RA, van Wijngaarden JP, et al. Cognitive Performance: A Cross-Sectional Study on Serum Vitamin D and Its Interplay With Glucose Homeostasis in Dutch Older Adults. J Am Med Dir Assoc 2015;16:621-7.

10. Jakobsen J, Ovesen L, Fagt S, et al. Para-aminobenzoic acid used as a marker for completeness of 24 hour urine: assessment of control limits for a specific HPLC method. Eur J Clin Nutr 1997;51:514-9.

11. Hagfors L, Westerterp K, Sköldstam L, et al. Validity of reported energy expenditure and reported intake of energy, protein, sodium and potassium in rheumatoid arthritis patients in a dietary intervention study. Eur J Clin Nutr 2005;59:238-45.

12. Meijboom S, van Houts-Streppel MT, Perenboom C, et al. Evaluation of dietary intake assessed by the Dutch selfadministered web-based dietary $24-\mathrm{h}$ recall tool (Compl-eat ${ }^{\mathrm{TM}}$ ) against interviewer-administered telephone-based $24-\mathrm{h}$ recalls. $J$ Nutr Sci 2017;6:e49.

13. van Strien T, Frijters JER, Bergers GPA, et al. The Dutch Eating Behavior Questionnaire (DEBQ) for assessment of restrained, emotional, and external eating behavior. Int $J$ Eat Disord 1986;5:295-315.

14. Steptoe A, Pollard TM, Wardle J. Development of a measure of the motives underlying the selection of food: the food choice questionnaire. Appetite 1995;25:267-84

15. Pliner $P$, Hobden K. Development of a scale to measure the trait of food neophobia in humans. Appetite 1992;19:105-20.

16. Sasaki S, Katagiri A, Tsuji T, et al. Self-reported rate of eating correlates with body mass index in 18-y-old Japanese women. Int J Obes Relat Metab Disord 2003;27:1405-10.

17. Fishbein MAJ. Predicting and changing behavior: the reasoned action approach. New York, NY: Psychology Press, 2010.

18. Honkanen P, Olsen SO, Verplanken B. Intention to consume seafood-the importance of habit. Appetite 2005;45:161-8.

19. Verplanken B, Orbell S. Reflections on past behavior: a self-report index of habit strength1. J Appl Soc Psychol 2003;33:1313-30.

20. Nelson Laska M, Larson NI, Neumark-Sztainer D, et al. Dietary patterns and home food availability during emerging adulthood: do they differ by living situation? Public Health Nutr 2010;13:222-8.

21. Kjeldahl J. Neue Methode zur Bestimmung des Stickstoffs in organischen Körpern. Fresenius, Zeitschrift $f$ anal Chemie 1883;22:366-82.

22. Holbrook JT, Patterson KY, Bodner JE, et al. Sodium and potassium intake and balance in adults consuming self-selected diets. $A m \mathrm{~J}$ Clin Nutr 1984;40:786-93.

23. Freisling $\mathrm{H}$, van Bakel MM, Biessy $\mathrm{C}$, et al. Dietary reporting errors on $24 \mathrm{~h}$ recalls and dietary questionnaires are associated with BMI 
across six European countries as evaluated with recovery biomarkers for protein and potassium intake. Br J Nutr 2012;107:910-20.

24. Bingham SA. Urine nitrogen as a biomarker for the validation of dietary protein intake. J Nutr 2003:133:921S-4.

25. Genant HK, Engelke K, Fuerst T, et al. Noninvasive assessment of bone mineral and structure: state of the art. J Bone Miner Res 1996;11:707-30.

26. Meerwaldt R, Graaff R, Oomen PHN, et al. Simple non-invasive assessment of advanced glycation endproduct accumulation. Diabetologia 2004;47:1324-30.

27. Mulder DJ, Water TV, Lutgers HL, et al. Skin autofluorescence, a novel marker for glycemic and oxidative stress-derived advanced glycation endproducts: an overview of current clinical studies, evidence, and limitations. Diabetes Technol Ther 2006;8:523-35.

28. Boutouyrie P. New techniques for assessing arterial stiffness. Diabetes Metab 2008;34(Suppl 1):21-6.

29. Laurent S, Cockcroft J, Van Bortel L, et al. Expert consensus document on arterial stiffness: methodological issues and clinical applications. Eur Heart J 2006;27:2588-605.

30. Nichols WW. Clinical measurement of arterial stiffness obtained from noninvasive pressure waveforms. Am J Hypertens 2005;18(1 Pt 2):3-10.

31. Allain CC, Poon LS, Chan CS, et al. Enzymatic determination of total serum cholesterol. Clin Chem 1974;20:470-5.

32. Friedewald WT, Levy RI, Fredrickson DS. Estimation of the concentration of low-density lipoprotein cholesterol in plasma, without use of the preparative ultracentrifuge. Clin Chem 1972;18:499-502.

33. Dumas BT, Watson WA, Biggs HG. Albumin standards and the measurement of serum albumin with bromcresol green. 1971. Clin Chim Acta 1997;258:21-30.

34. Levey AS, Bosch JP, Lewis JB, et al. A more accurate method to estimate glomerular filtration rate from serum creatinine: a new prediction equation. Modification of Diet in Renal Disease Study Group. Ann Intern Med 1999;130:461-70.

35. Levey AS, Coresh J, Greene T, et al. Using standardized serum creatinine values in the modification of diet in renal disease study equation for estimating glomerular filtration rate. Ann Intern Med 2006;145:247-54.

36. Levey AS, Stevens LA, Schmid CH, et al. A new equation to estimate glomerular filtration rate. Ann Intern Med 2009;150:604-12.

37. Smith A. The symbol-digit modalities test: a neuropsychologic test of learning and other cerebral disorders. Helmuth J, ed. Learning disorders. Seattle: Special child publications, 1968:83-91.

38. Smith A. Symbol Digits Modalities test. Los Angeles: Symbol Digits Modalities test, 1982.

39. Wilson B, Cockburn J, Baddeley A. The rivermeid behavioral Memory Test. Suffolk: Thames Valley Test Company, 1985.

40. Van der Elst W, Van Boxtel MP, Van Breukelen GJ, et al. Normative data for the Animal, Profession and Letter M Naming verbal fluency tests for Dutch speaking participants and the effects of age, education, and sex. J Int Neuropsychol Soc 2006;12:80-9.

41. Crandal R. The Measurements of self-esteem and related contructs. Robinson JS PR, ed. Measures fo social psychological attitudes Revised Edition. Ann Arbor: ISR, 1973.

42. Rosenberg M. Society and the Adolescent Self-Image. Revised Edition. Middletown, CT: Wesleyan University Press, 1989.

43. Tangney JP, Baumeister RF, Boone AL. High self-control predicts good adjustment, less pathology, better grades, and interpersonal success. J Pers 2004;72:271-324.
44. Nieboer A, Lindenberg S, Boomsma A, et al. Dimensions Of WellBeing And Their Measurement: The Spf-II Scale. Soc Indic Res 2005;73:313-53.

45. Brown KW, Ryan RM. The benefits of being present: mindfulness and its role in psychological well-being. J Pers Soc Psychol 2003;84:822-48.

46. Strathman A, Gleicher F, Boninger DS, et al. The consideration of future consequences: Weighing immediate and distant outcomes of behavior. J Pers Soc Psychol 1994;66:742-52.

47. Antonovsky $A$. The structure and properties of the sense of coherence scale. Soc Sci Med 1993;36:725-33.

48. Cohen S, Kamarck T. Mermelstein R. A Global Measure of Perceived Stress. Journal of Health and Social Behavior 1983;24:385-96.

49. Cohen S, Williamsom GM. Perceived Stress in a Probability Sample of the United States. In: Spacapn S, Oskamp S, eds. The Social Psychology of Health. Newbury Park, CA: Sage, 1988:31-67.

50. Hendriks AAJ, Ormel J, van de Willige G. Langdurige moeilijkheden gemeten volgens zelfbeoordelingsvragenlijst en semi-gestructureerd interview. Een theoretisch en emperische vergelijking. Gedrag en Gezondheid 1990;18:273-83.

51. Radloff LS. The CES-D Scale: A Self-Report Depression Scale for Research in the General Population. Applied Psychological Measurement 1977;1:385-401.

52. VanderZee KI, Sanderman R, Heyink JW, et al. Psychometric qualities of the RAND 36-Item Health Survey 1.0: a multidimensional measure of general health status. Int J Behav Med 1996;3:104-22.

53. Drossman DA. The functional gastrointestinal disorders and the Rome III process. Gastroenterology 2006;130:1377-90.

54. Drossman DA, Dumitrascu DL. Rome III: New standard for functional gastrointestinal disorders. J Gastrointestin Liver Dis 2006;15:237-41.

55. Roenneberg T, Wirz-Justice A, Merrow M. Life between clocks: daily temporal patterns of human chronotypes. J Biol Rhythms 2003;18:80-90

56. Scholtens S, Smidt N, Swertz MA, et al. Cohort Profile: LifeLines, a three-generation cohort study and biobank. Int J Epidemiol 2015;44:1172-80.

57. Wendel-Vos GC, Schuit AJ, Saris WH, et al. Reproducibility and relative validity of the short questionnaire to assess health-enhancing physical activity. J Clin Epidemiol 2003;56:1163-9.

58. Chinapaw MJ, Slootmaker SM, Schuit AJ, et al. Reliability and validity of the Activity Questionnaire for Adults and Adolescents (AQUAA). BMC Med Res Methodol 2009;9:58.

59. Sluik D, Brouwer-Brolsma EM, de Vries JH, et al. Associations of alcoholic beverage preference with cardiometabolic and lifestyle factors: the NQplus study. BMJ Open 2016;6:e010437.

60. Botros N, Sluik D, van Waateringe RP, et al. Advanced glycation endproducts (AGEs) and associations with cardio-metabolic, lifestyle, and dietary factors in a general population: the NQplus study. Diabetes Metab Res Rev 2017;33:e2892.

61. van Lee L, Feskens EJ, Meijboom S, et al. Evaluation of a screener to assess diet quality in the Netherlands. Br J Nutr 2016;115:517-26.

62. Mozaffarian D, Benjamin EJ, Go AS, et al. Heart disease and stroke statistics--2015 update: a report from the American Heart Association. Circulation 2015;131:e29-322.

63. Trijsburg L, de Vries JH, Boshuizen HC, et al. Comparison of duplicate portion and $24 \mathrm{~h}$ recall as reference methods for validating a FFQ using urinary markers as the estimate of true intake. Br J Nutr 2015;114:1304-12. 